\title{
Batch washing of lead contaminated and spiked soils using extracts of dried Terminalia mantaly, Panicum maximum and Eleusine indica plants
}

\author{
Effiong Ukorebi ETIM* \\ Department of Chemistry, University of Ibadan, Ibadan, Nigeria
}

\begin{abstract}
Application of dried plant water soluble extracts in soil $\mathrm{Pb}$ decontamination is rear, but advantageous due to their ecological biodegradability. Single batch laboratory scale suitability of Terminalia mantaly, Panicum maximum, Eleusine indica and water as washing solutions for $\mathrm{Pb}$ removal from contaminated and spiked soils at different soil pulp densities $(3 \%, 6 \%, 9 \%, 12 \%, 15 \%$ and 18\%) and washing time $(1,3,6,12,24$ and $96 \mathrm{~h})$ was investigated. Washings of Terminalia mantaly and Panicum maximum proved more efficient comparatively for contaminated soil with $\mathrm{Pb}$ removal efficiency of $27.2 \pm 0.64 \%$ and $27.0 \pm 0.52 \%$ respectively at $3 \%$ soil pulp density and washing time of $96 \mathrm{~h}$. Removal efficiency increased with increasing washing time but decreased with increasing of soil pulp density. Furthermore, water was found effective for removing $\mathrm{Pb}$ from spiked soils with maximum removal efficiency of $74.5 \pm 3.38 \%$ at $3 \%$ soil pulp density after $1 \mathrm{~h}$ washing. High exchangeable fraction of $\mathrm{Pb}(81.2 \%)$ in spiked soil makes water more suitable against other washing solutions. Statistical $t$-testing showed significant difference in $\mathrm{Pb}$ removal efficiency between contaminated and spiked soils for all four washing solutions, reflecting differences in geochemical phases of $\mathrm{Pb}$ in both soils. Terminalia mantaly and Panicum maximum showed promising result in soil washing and have potential for application in $\mathrm{Pb}$ removal from contaminated soils. However, chemical modifications are needed to enhance and improve on their efficiencies. Similarly, more information is needed to predict and model removal efficiencies when multiple washing steps are applied.
\end{abstract}

Keywords: heavy metals; plant extracts; removal efficiency; soils remediation; soil washing.

\section{Introduction}

Soil contamination is considered one significant environmental problem of the industrial age with greater footprints in developing countries [1]. Several contaminants such as heavy metals have been identified and classified of which lead is one with greater concern [2]. Lead contamination of soils could arise through emissions from rapidly expanding industrial areas, mining/smelting, shooting range and landfill activities among others [3-5]. The problem with lead in soils is their non-biodegradable nature, persistency, mobility and bio-accumulative potentials [6-8].

Lead constitutes an ill-defined group of inorganic chemicals which has been identified and considered one of the hazardous metals included in the US Environmental Protection Agency's (EPA) list of priority pollutants [9]. The presence of toxic lead in soils can severely inhibits soil ecology and contamination may pose direct risks and hazards to humans and animals [2, $10]$. It's therefore of essence to adequately protect and possibly restore lead contaminated soil ecosystems through characterization and remediation. Soil washing offers the greatest advantage of highly effective removal efficiency of lead in contaminated soils and is among the best demonstrated available techniques listed for remediation [11, 12]. A range of applications, for strong acids [13, 14], weak organic acids [15-17], chelating agents [18], fluids or gases [19] and even water, have proven effective but with certain degree of limitations.
For instance, strong acids decrease soil productivity while chelating agents are non-biodegradable [20-22].

The retention of the original soil ecology/chemistry after chemical washing has always been a priority due to the destructive actions of most washing solutions. These have caused increasing interest in research towards the use of soil friendly washing compounds, examples are the use of plant-derived compounds (such as biosurfactants) for soil remediation [23-28]. However, research in this area is still very limited. Furthermore, dried plant water-soluble extracts have found wide application in medicine, cosmetics and beverages. However, little or no scientific researches have reported the environmental applications of dried plant watersoluble extracts in metal contaminated soil remediation. Adaptation of dried plant derived water-soluble extracts as washing solution for soil remediation offers the advantage of biodegradability, availability, low cost, nontoxic and ecologically sustainable in restoring contaminated soils for agricultural purposes and enhanced food security [29].

This study solely investigates the use of naturally available water-soluble extracts from dried Terminalia mantaly, Panicum maximum and Eleusine indica, in enhancing solubilization and removal of lead from contaminated shooting range soils and laboratory spiked soils (artificially contaminated). The removal efficiency optimization was assessed by varying different factors such as soil pulp density (SPD) and washing time. Information obtained from this study will further aid in

\footnotetext{
*E-mail address: etim242@yahoo.com
} 
designing ecologically friendly natural plant-derived extracts for soil-metal remediation.

\section{Experimental}

\subsection{Soil sampling, preparation and spiking}

The washing experiment was conducted on two soil samples, i.e. field contaminated and artificially contaminated, collected from different locations. Field contaminated soil sample (depth $0-30 \mathrm{~cm}$, about $5 \mathrm{~kg}$ ) was collected within the impact berm of a major and active military shooting range, while soil for artificial contamination (depth $0-30 \mathrm{~cm}$, about $5 \mathrm{~kg}$ ) was collected from a remote location free from major pollutant derived activities. Sampling was carried out using stainless steel trowel after which air dried, homogenized and ground to pass through a $2 \mathrm{~mm}$ mesh sieve. The artificially contaminated soil (spiked soil) was spiked with $1000 \mathrm{~mL} \mathrm{~Pb}\left(\mathrm{NO}_{3}\right)_{2}$ at a concentration of $10,000 \mathrm{mg} / \mathrm{L}$. The sample was homogenized by shaking for $48 \mathrm{~h}$ and left to dry at room temperature for three weeks, after which was dried at $103-105^{\circ} \mathrm{C}$ to a constant weight and further mixed.

\subsection{Preparation of water soluble plant extract}

Three locally available plant species, i.e. Terminalia mantaly, Panicum maximum and Eleusine indica, were chosen for the experiment. These plant species are locally abundant, cheap to asses, and are of no economic importance. The aerial parts of plants were collected, washed and air dried in the laboratory at room temperature. The dried plant samples were ground and sieved through a $4 \mathrm{~mm}$ sieve. $1 \mathrm{~kg}$ weight of each sieved dried plant sample was homogenized with $35 \mathrm{~L}$ deionized water for $24 \mathrm{~h}$ using a mechanical stirrer (Griffin and George Limited KQPS/34). The extracts were then filtered and stored below $20{ }^{\circ} \mathrm{C}$ for the batch washing experiment.

\subsection{Batch soil washing experiment}

The single batch washing experiment was designed to assess the efficiency of water soluble plant extracts obtained from Terminalia mantaly, Panicum maximum and Eleusine indica, and water on $\mathrm{Pb}$ removal from contaminated and spike soil samples. The variables considered are SPD and washing time. The soil washing experiment was adapted from our previously published article [17].

For the contaminated soil, the washing experiments were conducted by weighing $3,6,9,12,15$ and $18 \mathrm{~g}$ of soil into six plastic bottles, in which $100 \mathrm{~mL}$ washing solution obtained from Terminalia mantaly was added. This is equivalent to $3 \%, 6 \%, 9 \%, 12 \%, 15 \%$ and $18 \%$ soil pulp density, calculated as:

$$
\operatorname{SPD}(\%)=\frac{m_{s}}{V_{\text {sol }}} \times 100
$$

where $m_{\mathrm{s}}=$ mass of soil $(\mathrm{g}), V_{\text {sol }}=$ volume of added solution, meaning aqueous extract or water $(\mathrm{mL})$.

The bottles were placed on an end-to-end (Edmund Buhler SM 25) mechanical shaker and extracted for $1 \mathrm{~h}$ after which the mixtures were filtered using Whatman (Cat No 1001, $110 \mathrm{~mm}$ ) filter paper.
The soil residue in the filter paper was then washed with deionized water sequentially twice and both supernatants from the initial leaching and washing were combined and stored for analysis. The agitation process was repeated for 3, 6, 12, 24 and $96 \mathrm{~h}$ intervals with same weight/volume of contaminated soil and Terminalia mantaly washing solutions.

A series of three other batch washing, using $100 \mathrm{~mL}$ of Panicum maximum and Eleusine indica extracts, and water, on the contaminated soil was repeated following the same procedure as for Terminalia mantaly washing solution.

The entire experiment was repeated using $100 \mathrm{~mL}$ Terminalia mantaly, Panicum maximum, Eleusine indica, and water following the same weight/volume and interval agitating of 1 to $96 \mathrm{~h}$ for the spiked soil sample.

The supernatants from each washing experiment were digested with $2 \mathrm{~mL}$ concentrated nitric acid, filtered and make to mark in $100 \mathrm{~mL}$ standard flasks and stored for $\mathrm{Pb}$ determination. The resulted solutions were analyzed for $\mathrm{Pb}$ using Varian SpectrAA 600 flame atomic absorption spectrophotometer.

The percentage removal efficiency of $\mathrm{Pb}$ from soil samples (either contaminated or spiked soil) was calculated using the following equation $[17,30,31]$ :

$$
\text { Removal efficiency }(\%)=\frac{C_{1} \times V_{1}}{C_{s} \times m_{s}} \times 100
$$

where $C_{1}$ and $C_{\mathrm{S}}$ are the concentrations of $\mathrm{Pb}$ in the supernatants $(\mathrm{mg} / \mathrm{L})$ and soil samples $(\mathrm{mg} / \mathrm{kg})$ determined using FAAS, $V_{1}$ is the volume of supernatants (L), and $m_{\mathrm{S}}$ is the weight of the soil $(\mathrm{kg})$ used for the washing experiment.

Each batch washing experiment was performed in triplicate and the calculated standard deviation of triplicate analysis performed on extracts from each batch washing experiment ranged within 5\%. These average values are shown in Tables 3 and 4.

\subsection{Analytical methods}

The soils' $\mathrm{pH}$ values were measured in deionized water using a solid : liquid ratio of $1: 1(\mathrm{w} / \mathrm{v})$ following $1 \mathrm{~h}$ shaking and filtration through a Whatman (Cat No 1001, $110 \mathrm{~mm}$ ) filter paper [32], while $\mathrm{pH}$ of the washing solutions were measured directly using a $\mathrm{pH}$ meter (Hanna Instruments). Particle size analysis was carried out using the hydrometric method [33]. Soil organic carbon content was determined by Walkley and Black method [34], available phosphate was determined by the Bray No. 1 method [35], and soil nitrate was determined by distillation method following extraction with $2 \mathrm{M} \mathrm{KCl}$ solution [36]. Cation exchange capacity was determined using $1 \mathrm{M}$ ammonium acetate at $\mathrm{pH} 7$ as the exchangeable base [37]. Total lead concentration in the contaminated and spike soils was determined using $\mathrm{HCl}$ : $\mathrm{HNO}_{3}$ mixture on a hot plate. Procedurally, on $5.0 \mathrm{~g}$ of each soil were added $50 \mathrm{~mL}$ of $\mathrm{HCl}: \mathrm{HNO}_{3}$ mixture at $3: 1$ ratio $(\mathrm{v} / \mathrm{v})$ and heated on a hot plate for $3 \mathrm{~h} \mathrm{[38].} \mathrm{After}$ cooling the extracts were filtered through Whatman (Cat No $1001,110 \mathrm{~mm}$ ) filter paper, made to a $50 \mathrm{~mL}$ standard volumetric flask and analyzed for total lead using Varian SpectrAA 600 flame atomic absorption spectrophotometer. Speciation of lead fractions was 
carried out by Tessier sequential extraction scheme [39] to obtain exchangeable, carbonate, reducible, oxidizable and residual fractions of lead in the soils.

\subsection{Quality control and assurance}

Supernatants from the washing experiment were analyzed in triplicates as stated above. Split samples were incorporated for instrument data validation. A $t$-test showed no significant differences in actual and slit results. Analar grade (Sigma-Aldrich) reagents were used for the experiment. The Varian SpectrAA 600 flame atomic absorption spectrophotometer was calibrated using 1, 3, 5, and $10 \mathrm{mg} / \mathrm{L}$ REHHGFT working standards.

\section{Results and discussion}

\subsection{Soil and washing solution characterization}

The characterization of the experimental soils and washing solutions is given in Tables 1 and 2 .

Table 1. Characteristics of experimental soils and washing solutions $(n=3)$.

\begin{tabular}{|l|c|c|c|c|c|c|}
\hline \multicolumn{1}{|c|}{ Parameter } & Contaminated soil & Spiked soil & $\begin{array}{c}\text { Treminalia } \\
\text { mantaly }\end{array}$ & $\begin{array}{c}\text { Panicum } \\
\text { maximum }\end{array}$ & $\begin{array}{c}\text { Eleusine } \\
\text { indica }\end{array}$ & Water \\
\hline $\mathrm{pH}$ & 5.93 & 5.70 & 4.78 & 5.48 & 5.97 & 5.53 \\
\hline Sand content (\%) & 65.6 & 63.4 & - & - & - & - \\
\hline Silt content (\%) & 19.2 & 22.7 & - & - & - & - \\
\hline Clay content (\%) & 15.2 & 13.8 & - & - & - & - \\
\hline Organic carbon (\%) & 2.22 & 3.09 & - & - & - & - \\
\hline Organic matter (\%) & 3.84 & 5.34 & & & & - \\
\hline CEC (cmol/kg) & 112 & 103 & - & - & - & - \\
\hline Nitrate $(\mathrm{mg} / \mathrm{kg})$ & 25.3 & 27.8 & - & - & - & - \\
\hline Phosphate $(\mathrm{mg} / \mathrm{kg})$ & 15.7 & 16.2 & - & - & - & - \\
\hline Lead & $15207 \pm 8008 \mathrm{mg} / \mathrm{kg}$ & $2441 \pm 77 \mathrm{mg} / \mathrm{kg}$ & $0.00 \mathrm{mg} / \mathrm{L}$ & $0.00 \mathrm{mg} / \mathrm{L}$ & $0.00 \mathrm{mg} / \mathrm{L}$ & $0.00 \mathrm{mg} / \mathrm{L}$ \\
\hline
\end{tabular}

$n$ - number of samples analyzed; CEC - cation exchange capacity.

The $\mathrm{pH}$ values of the contaminated (5.93) and spiked (5.70) soils were about the same, which is indicative of an oxidative soil. These soil types are known for their ability to chemically enhanced metal mobility depending on short-term fluctuations in moisture and redox potentials [40].

Table 2. Lead speciation (\% geochemical phases) in experimental soils $(n=3)$.

\begin{tabular}{|l|c|c|}
\hline \multirow{2}{*}{\multicolumn{1}{|c|}{ Parameter }} & \multicolumn{2}{|c|}{ Pb [mg/kg] } \\
\cline { 2 - 3 } & $\begin{array}{c}\text { Contaminated } \\
\text { soil }\end{array}$ & Spiked soil \\
\hline Exchangeable metal & 3.02 & 81.2 \\
\hline $\begin{array}{l}\text { Metal bound to } \\
\text { carbonates }\end{array}$ & 32.6 & 3.30 \\
\hline $\begin{array}{l}\text { Metal bound to Fe- } \\
\text { Mn oxides }\end{array}$ & 18.4 & 5.74 \\
\hline $\begin{array}{l}\text { Metal bound to } \\
\text { organic matter }\end{array}$ & 11.9 & 3.30 \\
\hline Residual metal & 34.1 & 6.56 \\
\hline
\end{tabular}

$n$ - number of samples analyzed.

The organometric fractions of both soils showed a characteristic "sandy-loamy" property with high sand and silt contents and also low organic matter and cation exchange capacity. Nitrate and phosphate levels in both soils were also of about same values. The contaminated and spike soil samples are therefore of similar characteristics (sandy-loamy) with ability to enhance metal mobility and suitable for the washing experiment, to assess their ability to release adsorbed metals. Average lead level in contaminated soil $(15207 \pm 8008 \mathrm{mg} / \mathrm{kg})$ is much higher than in spike soil (244 $1 \pm 77 \mathrm{mg} / \mathrm{kg})$ due to contamination sources.

From speciation study shown in Table 2, average bioavailable (non-residual) fraction was lower in the contaminated soil $(65.9 \%)$ as against the spike soil (93.4\%), indications of the sources and treatment methods for both soil samples. The most mobile of the bioavailable fractions, the exchangeable fraction was similarly lower in the contaminated soil $(3.11 \%)$ than in spiked soil $(81.2 \%)$. The contaminated soil showed similar characteristics to previous studies [17, 41].

The $\mathrm{pH}$ values of the extracts (Table 1) were generally acidic in order of: Eleusine indica (5.97) > water (5.53) > Panicum maximum (5.48) > Terminalia mantaly (4.78), while lead levels were non-detectable in all extracts. A lower $\mathrm{pH}$ value of any washing solution is an important index in evaluating its solubilization potential for metals from contaminated soils. It can be inferred that lower $\mathrm{pH}$ may favor greater washing potential especially for Terminalia mantaly (4.78).

\subsection{Removal efficiency of lead from contaminated soil}

Table 3 shows percentage removal efficiency of $\mathrm{Pb}$ from contaminated soil using water soluble extracts and water as washing solutions.

Table 3. Percentage removal efficiency of $\mathrm{Pb}$ from contaminated soil.

\begin{tabular}{|c|c|c|c|c|c|}
\hline $\begin{array}{c}\text { Washing time } \\
{[\mathbf{h}]}\end{array}$ & $\begin{array}{c}\text { Soil pulp density } \\
{[\mathbf{\%}]}\end{array}$ & $\begin{array}{c}\text { Treminalia } \\
\text { mantaly }\end{array}$ & $\begin{array}{c}\text { Panicum } \\
\text { maximum }\end{array}$ & Eleusine indica & Water \\
\hline \multirow{6}{*}{$\mathbf{1}$} & 3 & $6.14 \pm 0.03$ & $16.4 \pm 0.35$ & $4.82 \pm 0.17$ & $8.77 \pm 0.45$ \\
\cline { 2 - 6 } & 6 & $6.91 \pm 0.11$ & $8.99 \pm 0.12$ & $3.84 \pm 0.11$ & $4.82 \pm 0.21$ \\
\cline { 2 - 6 } & 9 & $5.48 \pm 0.13$ & $7.23 \pm 0.09$ & $2.92 \pm 0.10$ & $6.50 \pm 0.37$ \\
\cline { 2 - 6 } & 12 & $4.71 \pm 0.12$ & $6.52 \pm 0.12$ & 0.00 & $1.92 \pm 0.10$ \\
\cline { 2 - 6 } & 15 & $3.90 \pm 0.04$ & $7.32 \pm 0.11$ & 0.00 & $1.32 \pm 0.06$ \\
\cline { 2 - 6 } & 18 & $3.18 \pm 0.10$ & $4.46 \pm 0.10$ & $2.48 \pm 0.11$ & $2.30 \pm 0.12$ \\
\hline 3 & 3 & $13.6 \pm 0.26$ & $21.5 \pm 0.22$ & $16.0 \pm 0.46$ & $12.1 \pm 0.41$ \\
\hline
\end{tabular}




\begin{tabular}{|c|c|c|c|c|c|}
\hline $\begin{array}{c}\text { Washing time } \\
{[\mathrm{h}]}\end{array}$ & $\begin{array}{c}\text { Soil pulp density } \\
{[\%]}\end{array}$ & $\begin{array}{c}\text { Treminalia } \\
\text { mantaly }\end{array}$ & $\begin{array}{l}\text { Panicum } \\
\text { maximum }\end{array}$ & Eleusine indica & Water \\
\hline & 6 & $8.00 \pm 0.03$ & $12.0 \pm 0.24$ & $7.50 \pm 0.12$ & $5.59 \pm 0.11$ \\
\hline & 9 & $9.35 \pm 0.02$ & $8.77 \pm 0.16$ & $2.48 \pm 0.04$ & $4.10 \pm 0.10$ \\
\hline & 12 & $7.67 \pm 0.03$ & $5.32 \pm 0.14$ & $1.26 \pm 0.01$ & $4.22 \pm 0.14$ \\
\hline & 15 & $4.52 \pm 0.03$ & $3.95 \pm 0.14$ & $0.48 \pm 0.03$ & $1.97 \pm 0.03$ \\
\hline & 18 & $5.30 \pm 0.02$ & $4.24 \pm 0.15$ & $0.26 \pm 0.02$ & $2.34 \pm 0.05$ \\
\hline \multirow[t]{6}{*}{6} & 3 & $22.1 \pm 0.13$ & $24.3 \pm 0.56$ & $4.00 \pm 0.10$ & $10.5 \pm 0.32$ \\
\hline & 6 & $12.5 \pm 0.11$ & $11.7 \pm 0.26$ & $3.51 \pm 0.12$ & $5.26 \pm 0.12$ \\
\hline & 9 & $12.2 \pm 0.10$ & $7.75 \pm 0.19$ & $0.94 \pm 0.05$ & $2.48 \pm 0.11$ \\
\hline & 12 & $9.43 \pm 0.07$ & $5.70 \pm 0.10$ & 0.00 & $2.63 \pm 0.11$ \\
\hline & 15 & $8.37 \pm 0.06$ & $6.23 \pm 0.16$ & 0.00 & $2.45 \pm 0.10$ \\
\hline & 18 & $7.27 \pm 0.05$ & $4.02 \pm 0.10$ & 0.00 & $1.68 \pm 0.06$ \\
\hline \multirow[t]{6}{*}{12} & 3 & $21.7 \pm 0.10$ & $22.4 \pm 0.36$ & 0.00 & $11.4 \pm 0.38$ \\
\hline & 6 & $12.1 \pm 0.13$ & $12.5 \pm 0.27$ & 0.00 & $4.84 \pm 0.13$ \\
\hline & 9 & $11.6 \pm 0.14$ & $7.60 \pm 0.31$ & 0.00 & $2.85 \pm 0.06$ \\
\hline & 12 & $6.41 \pm 0.08$ & $5.75 \pm 0.26$ & 0.00 & $1.86 \pm 0.03$ \\
\hline & 15 & $5.92 \pm 0.11$ & $4.30 \pm 0.11$ & 0.00 & $1.84 \pm 0.05$ \\
\hline & 18 & $6.06 \pm 0.12$ & $4.49 \pm 0.24$ & 0.00 & $1.94 \pm 0.08$ \\
\hline \multirow[t]{6}{*}{24} & 3 & $24.0 \pm 0.69$ & $22.4 \pm 0.18$ & 0.00 & $14.0 \pm 0.27$ \\
\hline & 6 & $16.3 \pm 0.77$ & $12.1 \pm 0.23$ & 0.00 & $3.29 \pm 0.16$ \\
\hline & 9 & $12.4 \pm 0.62$ & $7.53 \pm 0.22$ & 0.00 & $1.32 \pm 0.04$ \\
\hline & 12 & $10.4 \pm 0.31$ & $5.70 \pm 0.19$ & 0.00 & $0.26 \pm 0.03$ \\
\hline & 15 & $6.62 \pm 0.21$ & $4.30 \pm 0.07$ & 0.00 & $0.88 \pm 0.02$ \\
\hline & 18 & $6.94 \pm 0.11$ & $4.31 \pm 0.05$ & 0.00 & $0.80 \pm 0.04$ \\
\hline \multirow[t]{6}{*}{96} & 3 & $27.2 \pm 0.64$ & $27.0 \pm 0.52$ & 0.00 & $6.80 \pm 0.15$ \\
\hline & 6 & $19.4 \pm 0.31$ & $13.7 \pm 0.16$ & 0.00 & $4.60 \pm 0.11$ \\
\hline & 9 & $12.8 \pm 0.27$ & $10.0 \pm 0.15$ & 0.00 & $2.56 \pm 0.10$ \\
\hline & 12 & $12.4 \pm 0.41$ & $9.48 \pm 0.15$ & 0.00 & $0.88 \pm 0.04$ \\
\hline & 15 & $7.85 \pm 0.08$ & $5.04 \pm 0.12$ & 0.00 & $1.40 \pm 0.03$ \\
\hline & 18 & $8.11 \pm 0.11$ & $4.68 \pm 0.10$ & 0.00 & $0.88 \pm 0.04$ \\
\hline
\end{tabular}

The removal efficiency of $\mathrm{Pb}$ was generally very low $(<28.0 \%)$ for all four washing solutions. Nevertheless, washings of Terminalia mantaly and Panicum maximum extracts showed promising high values of $27.2 \pm 0.64 \%$ and $27.0 \pm 0.52 \%$ respectively, for single batch washing at $3 \%$ SDP and washing time of $96 \mathrm{~h}$. Meanwhile the highest of $16.0 \pm 0.46 \%$ was recorded for Eleusine indica and $12.1 \pm 0.41 \%$ for water, at $3 \%$ SPD and washing time of $3 \mathrm{~h}$. Washings of Terminalia mantaly and Panicum maximum extracts showed relatively consistent $\mathrm{Pb}$ removal efficiency with values slightly greater than $20 \%$, especially at $3 \%$ SPD. The $\mathrm{pH}$ values of these washing solutions may have played a significant role in $\mathrm{Pb}$ removal efficiency from the contaminated soil. Eleusine indica $(\mathrm{pH}=5.97)$ recorded the poorest removal efficiency of $\mathrm{Pb}$ with well over $50 \%$ of soil washings having $0.00 \%$, followed by water $(\mathrm{pH}=5.53)$ with about $10 \% \mathrm{~Pb}$ removal efficiency at $3 \%$ SPD irrespective of washing time. Furthermore, from speciation studies of Table 2, low exchangeable fraction $(3.02 \%)$ of $\mathrm{Pb}$ in the contaminated soil is another important factor that could explain the rather low washing potential of $\mathrm{Pb}$ by water and extracts of dried Terminalia mantaly, Panicum maximum and Eleusine indica plants. The other nonresidual fractions (carbonate, reducible and organic) may be difficult to extract considering the $\mathrm{pH}$ of the washing solutions.

Figure 1 shows trend in $\mathrm{Pb}$ removal efficiency in relation to washing time and SPD.
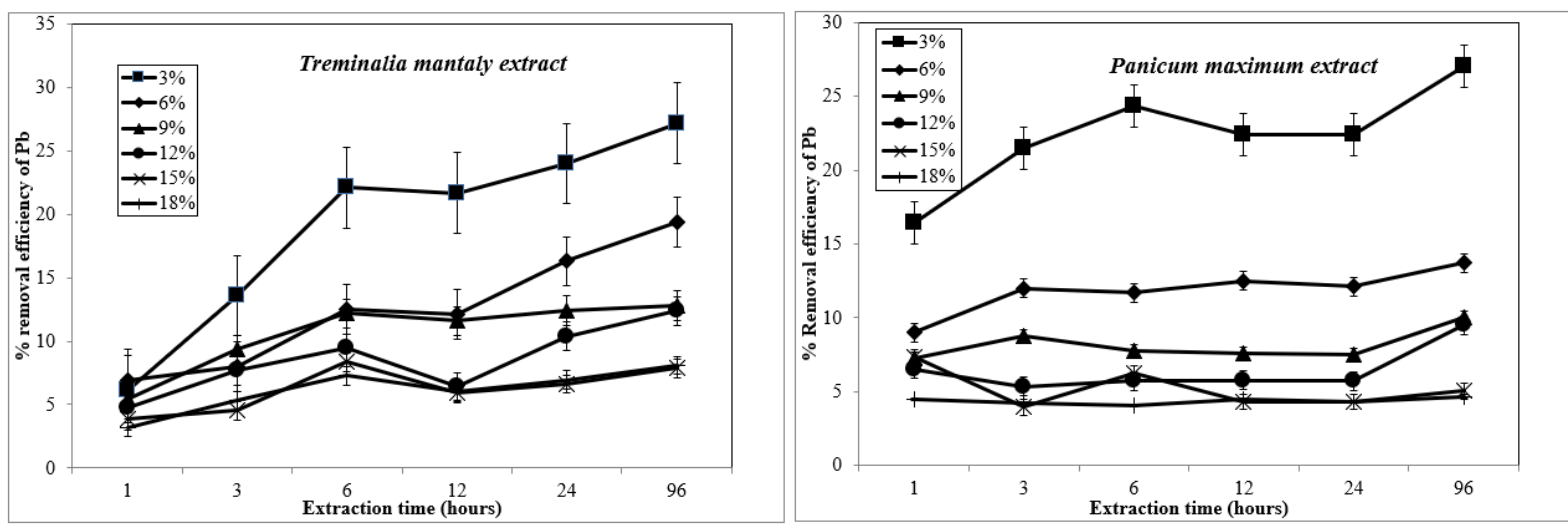

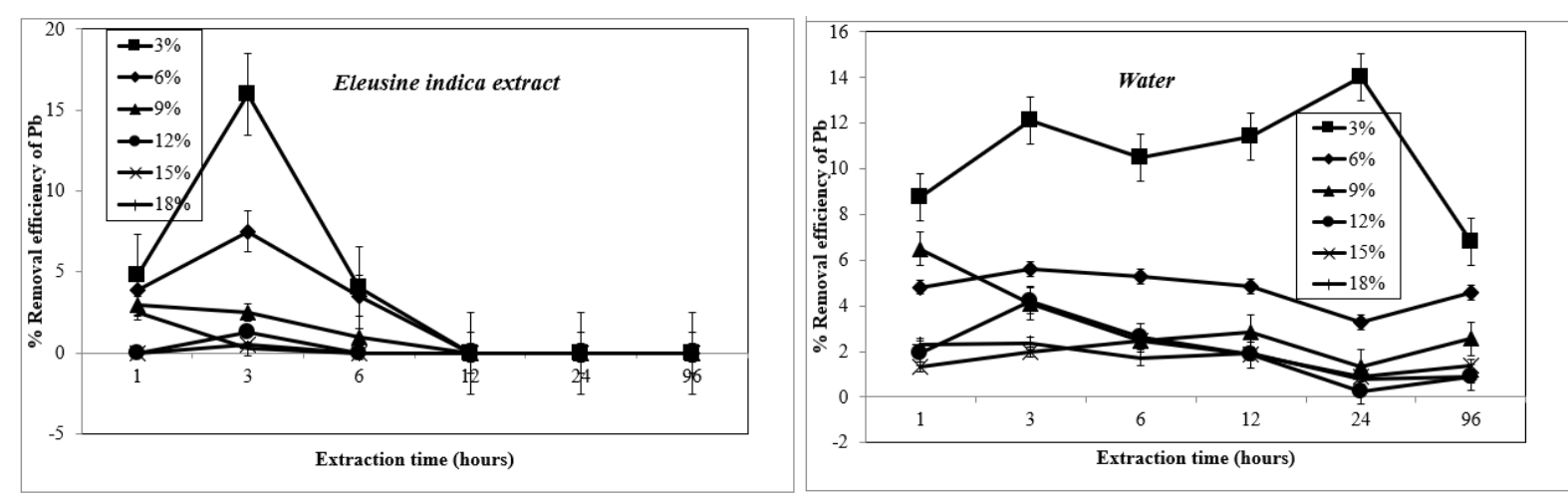

Figure 1. Removal efficiency (\%) of $\mathrm{Pb}$ from contaminated soil.

The 3\% SPD appears more favorable for $\mathrm{Pb}$ removal with removal efficiency significantly higher than for 6, 9, 12,15 and $18 \%$ SPD across all four washing solutions. Removal efficiency of $\mathrm{Pb}$ increased with increasing washing time except for Eleusine indica. This trend is similar to previously report soil decontamination experiment with SPD $=3 \%$ at increasing washing time showing promising removal efficiencies for $\mathrm{Pb}$ [17]. Test of significance was carryout using single factor analysis of variance at $p=0.05$. Percentage removal efficiency of $\mathrm{Pb}$ was significantly different among the four washing solutions factoring washing time and SPD.

\subsection{Removal efficiency of lead from spike soil}

The percentage removal efficiency of $\mathrm{Pb}$ from spike soil using extracts of Terminalia mantaly, Panicum maximum and Eleusine indica, and water as washing solutions is given in Table 4.

Table 4. Percentage removal efficiency of $\mathrm{Pb}$ from spiked soil.

\begin{tabular}{|c|c|c|c|c|c|}
\hline $\begin{array}{c}\text { Washing time } \\
{[\mathrm{h}]}\end{array}$ & $\begin{array}{c}\text { Soil pulp } \\
\text { density }\end{array}$ & $\begin{array}{c}\text { Treminalia } \\
\text { mantaly }\end{array}$ & $\begin{array}{l}\text { Panicum } \\
\text { maximum }\end{array}$ & Eleusine indica & Water \\
\hline \multirow[t]{6}{*}{1} & 3 & $19.7 \pm 0.43$ & $21.9 \pm 0.27$ & 0.00 & $74.5 \pm 3.38$ \\
\hline & 6 & $9.75 \pm 0.19$ & $10.5 \pm 0.23$ & 0.00 & $65.8 \pm 2.64$ \\
\hline & 9 & $6.28 \pm 0.14$ & $7.23 \pm 0.24$ & 0.00 & $38.2 \pm 1.64$ \\
\hline & 12 & $4.71 \pm 0.15$ & $5.59 \pm 0.18$ & 0.00 & $48.8 \pm 1.55$ \\
\hline & 15 & $3.46 \pm 0.11$ & $4.25 \pm 0.17$ & 0.00 & $30.9 \pm 1.10$ \\
\hline & 18 & $3.47 \pm 0.16$ & $3.76 \pm 0.14$ & 0.00 & $14.8 \pm 0.22$ \\
\hline \multirow[t]{6}{*}{3} & 3 & $19.7 \pm 0.32$ & $22.1 \pm 0.38$ & 0.00 & $63.4 \pm 2.17$ \\
\hline & 6 & $10.2 \pm 0.23$ & $11.5 \pm 0.19$ & 0.00 & $55.4 \pm 1.68$ \\
\hline & 9 & $7.09 \pm 0.17$ & $7.09 \pm 0.21$ & 0.00 & $45.5 \pm 2.34$ \\
\hline & 12 & $11.7 \pm 0.21$ & $5.75 \pm 0.12$ & 0.00 & $32.0 \pm 1.11$ \\
\hline & 15 & $4.34 \pm 0.06$ & $4.56 \pm 0.11$ & 0.00 & $12.8 \pm 0.63$ \\
\hline & 18 & $3.29 \pm 0.08$ & $3.80 \pm 0.12$ & 0.00 & $10.8 \pm 0.54$ \\
\hline \multirow[t]{6}{*}{6} & 3 & $25.6 \pm 0.52$ & $23.8 \pm 0.71$ & 0.00 & $46.5 \pm 1.16$ \\
\hline & 6 & $3.07 \pm 0.07$ & $11.7 \pm 0.22$ & 0.00 & $33.3 \pm 1.21$ \\
\hline & 9 & $0.15 \pm 0.01$ & $1.97 \pm 0.07$ & $5.26 \pm 0.13$ & $11.0 \pm 0.44$ \\
\hline & 12 & $0.05 \pm 0.02$ & $1.64 \pm 0.06$ & $0.60 \pm 0.02$ & $12.7 \pm 0.21$ \\
\hline & 15 & $0.52 \pm 0.03$ & $1.32 \pm 0.05$ & 0.00 & $11.0 \pm 0.11$ \\
\hline & 18 & $2.01 \pm 0.01$ & $1.39 \pm 0.05$ & $1.31 \pm 0.03$ & $5.89 \pm 0.26$ \\
\hline \multirow[t]{6}{*}{12} & 3 & $18.6 \pm 0.37$ & $8.55 \pm 0.11$ & 0.00 & $39.0 \pm 2.10$ \\
\hline & 6 & $4.49 \pm 0.09$ & $3.51 \pm 0.05$ & $3.07 \pm 0.02$ & $33.7 \pm 1.43$ \\
\hline & 9 & $2.63 \pm 0.06$ & $2.85 \pm 0.06$ & $1.53 \pm 0.02$ & $22.8 \pm 1.19$ \\
\hline & 12 & $2.52 \pm 0.06$ & $2.80 \pm 0.03$ & $1.86 \pm 0.03$ & $32.1 \pm 0.75$ \\
\hline & 15 & $1.67 \pm 0.03$ & $2.15 \pm 0.03$ & $0.04 \pm 0.01$ & $33.3 \pm 0.48$ \\
\hline & 18 & $0.29 \pm 0.01$ & $1.72 \pm 0.04$ & $1.21 \pm 0.04$ & $19.3 \pm 0.43$ \\
\hline \multirow[t]{6}{*}{24} & 3 & $12.1 \pm 0.31$ & $12.1 \pm 0.18$ & $5.92 \pm 0.31$ & $51.3 \pm 2.63$ \\
\hline & 6 & $8.44 \pm 0.10$ & $5.70 \pm 0.12$ & $5.26 \pm 0.22$ & $50.5 \pm 1.85$ \\
\hline & 9 & $0.88 \pm 0.03$ & $3.87 \pm 0.10$ & $3.21 \pm 0.14$ & $21.8 \pm 1.03$ \\
\hline & 12 & $3.73 \pm 0.10$ & $2.31 \pm 0.09$ & $2.08 \pm 0.11$ & $30.7 \pm 0.86$ \\
\hline & 15 & $2.32 \pm 0.07$ & $2.15 \pm 0.10$ & $0.53 \pm 0.02$ & $4.37 \pm 0.02$ \\
\hline & 18 & $1.46 \pm 0.01$ & $1.97 \pm 0.10$ & $2.05 \pm 0.07$ & $13.2 \pm 0.03$ \\
\hline \multirow[t]{6}{*}{96} & 3 & $9.43 \pm 0.11$ & $10.3 \pm 0.20$ & $8.54 \pm 0.18$ & $28.9 \pm 1.57$ \\
\hline & 6 & $7.01 \pm 0.23$ & $6.03 \pm 0.21$ & $4.93 \pm 0.14$ & $63.5 \pm 2.82$ \\
\hline & 9 & $3.14 \pm 0.15$ & $3.95 \pm 0.13$ & $1.10 \pm 0.05$ & $58.3 \pm 0.77$ \\
\hline & 12 & $2.96 \pm 0.11$ & $2.69 \pm 0.14$ & $2.80 \pm 0.04$ & $24.9 \pm 0.56$ \\
\hline & 15 & $2.10 \pm 0.06$ & $2.32 \pm 0.10$ & $1.80 \pm 0.03$ & $18.8 \pm 0.32$ \\
\hline & 18 & $2.52 \pm 0.04$ & $2.08 \pm 0.11$ & $1.49 \pm 0.04$ & $53.3 \pm 1.96$ \\
\hline
\end{tabular}


Spike soil was used for the washing experiment to assess removal efficiency of $\mathrm{Pb}$ in relation to contaminated soil, considering fractionated species of $\mathrm{Pb}$ in both soils. The use of water proved more efficient comparatively to other plant based washing solutions with removal efficiency ranging from $28.9 \pm 1.57 \%$ to $74.5 \pm 3.38 \%$ at $3 \%$ SPD, with highest value recorded in just $1 \mathrm{~h}$ washing time. This might be due to high exchangeable $(81.2 \%)$ fraction of $\mathrm{Pb}$ in spiked soil comparatively to contaminated soil. The addition of water efficiently enhanced the dissolution of aqueous phase soluble $\mathrm{Pb}$ from the soil particles. It is believed that the fractions including exchangeable, carbonates and reducible forms are the species amenable to soil washing
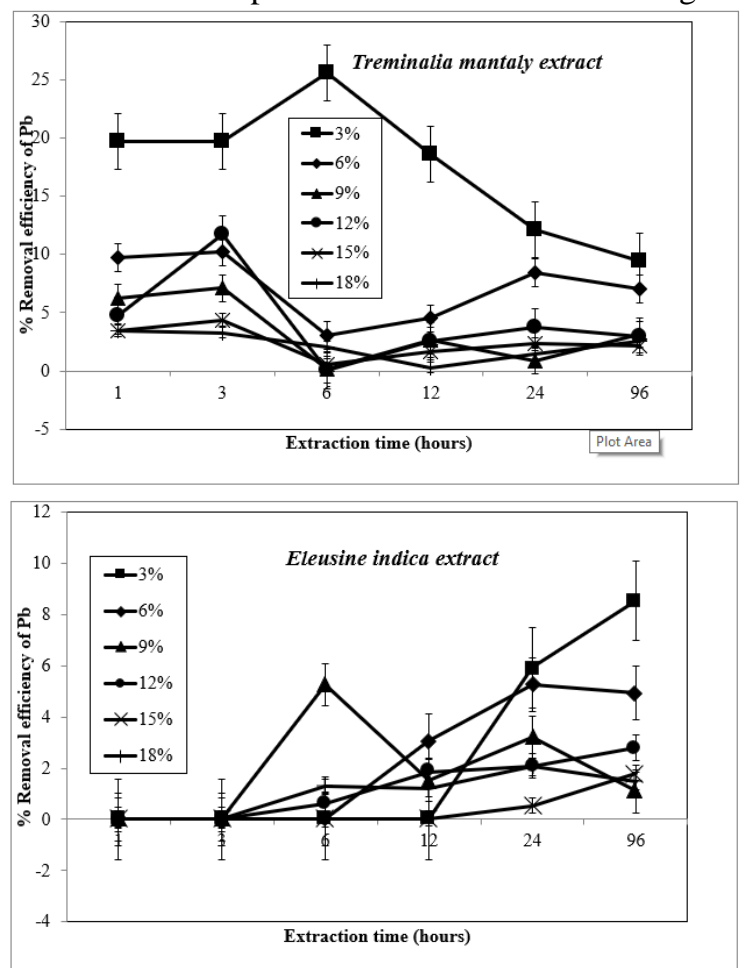

technique, whereas organic and residual forms are more stable not generally removed by soil washing [26, 42]. Terminalia mantaly had its highest removal efficiency of $25.6 \pm 0.52 \%$ followed by Panicum maximum of $23.8 \pm 0.71 \%$ at $3 \%$ SPD with 6 hours washing time. Eleusine indica washing solution reported the least of $8.54 \pm 0.18 \%$ at $3 \%$ SPD. The combine organic matter content of soil and washing Terminalia mantaly, Panicum maximum, and Eleusine indica solutions could make $\mathrm{Pb}$ removal quite difficult due to their high sportive capacity. Single factor analysis of variance at $p=0.05$ showed significant difference in removal efficiency of $\mathrm{Pb}$ from spike soil among all four washing solutions.
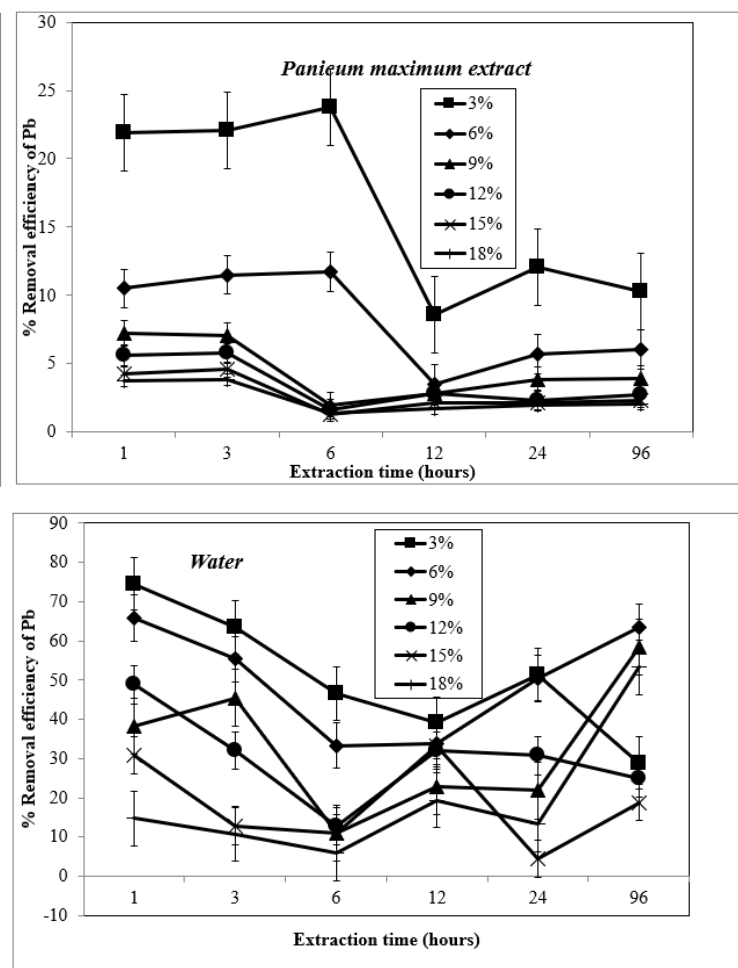

Figure 2. Removal efficiency (\%) of Pb from spiked soil.

Figure 2 showed a decreasing removal efficiency of $\mathrm{Pb}$ from spiked soil relative to washing time for Terminalia mantaly, Panicum maximum and water, except for Eleusine indica. The relative oversaturation of the washing solutions with soil particles (more soil weight to washing solution volume) could account for this trend.

Table 5. Pearson's correlation coefficient $(p=0.05)$ of contaminated and spiked soils.

\begin{tabular}{|c|c|c|c|}
\hline $\begin{array}{c}\text { Extraction } \\
\text { time [h] }\end{array}$ & $\begin{array}{c}\text { Treminalia } \\
\text { mantaly }\end{array}$ & $\begin{array}{c}\text { Panicum } \\
\text { maximum }\end{array}$ & Water \\
\hline 1 & 0.968 & 0.823 & 0.384 \\
\hline 3 & 0.672 & 0.969 & 0.954 \\
\hline 6 & 0.155 & 0.906 & 0.999 \\
\hline 12 & 0.778 & 0.892 & 0.292 \\
\hline 24 & 0.726 & 0.987 & 0.717 \\
\hline 96 & 0.946 & 0.919 & 0.659 \\
\hline
\end{tabular}

Statistical $t$-testing showed significant difference in $\mathrm{Pb}$ removal efficiency between contaminated and spiked soils for all four washing solutions, reflecting differences in geochemical phases of $\mathrm{Pb}$ in both soils.

Table 5 gives the correlation coefficients of $\mathrm{Pb}$ removal efficiency from contaminated and spiked soils.

Significant positive correlations were obtained for Terminalia mantaly, Panicum maximum and water for both soils. These suggest Terminalia mantaly and Panicum maximum extracts and water could apply to any soil type of varying degree of contamination.

Comparing $\mathrm{Pb}$ removal efficiency of the four washing solutions at 3\% SPD (Figure 3), Panicum maximum and Terminalia mantaly extracts proved more efficient than other washing solutions for contaminated soil as against water for spiked soil. Consequently, removal efficiency was found to significantly increase for contaminated soil with washing time while water extract of spiked soil decreased with washing time. Therefore, longer contact time for contaminated soil and Panicum maximum and Terminalia mantaly washing solutions could relatively be efficient for $\mathrm{Pb}$ remediation. This efficiency could further be improved upon using double or multiple batch experimental washings. 

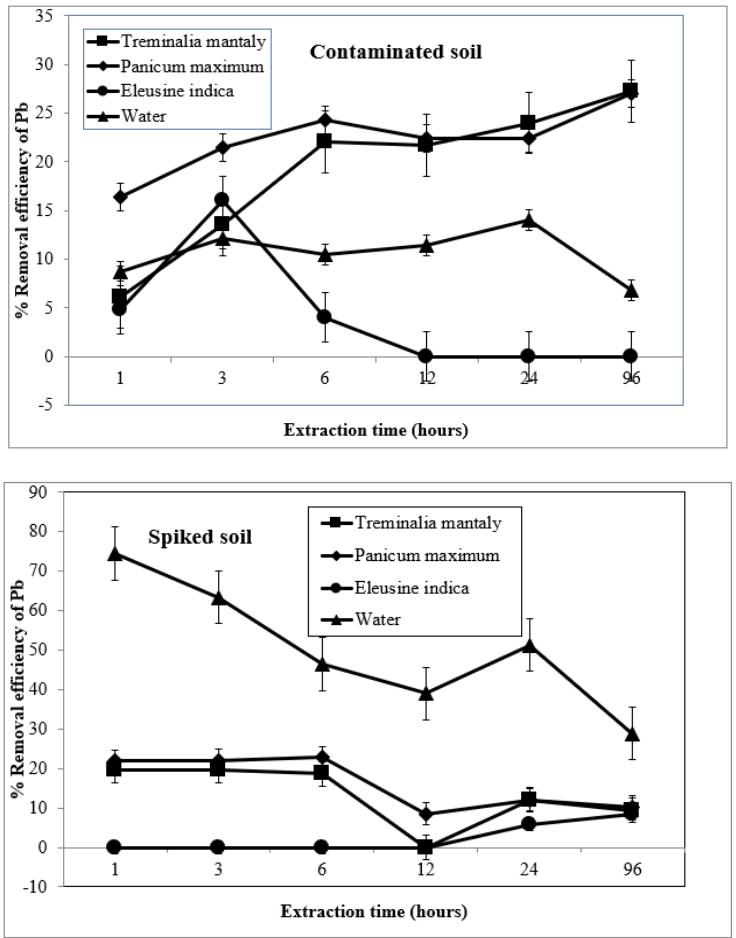

Figure 3. Removal efficiency (\%) of $\mathrm{Pb}$ from contaminated and spiked soils with $3 \%$ SPD.

\section{Conclusion}

In conclusion, washing of Terminalia mantaly, Panicum maximum and Eleusine indica solutions for $\mathrm{Pb}$ contaminated and spiked soils was conducted with single batch equilibrium experiments, and the washing efficiencies expressed with percentage removal of $\mathrm{Pb}$ from both soils. Washings of Terminalia mantaly and Panicum maximum proved more promising and more effective for $\mathrm{Pb}$ removal in contaminated and spiked soils at $3 \% \mathrm{SPD}$. Influence of $\mathrm{Pb}$ species in soil form determined to a greater extent removal efficiency of $\mathrm{Pb}$ particularly in the contaminated soil. The eco-friendly biodegradable water soluble extract of dried Terminalia mantaly and Panicum maximum can be used for environmental cleanup of $\mathrm{Pb}$ contaminated soils. However, successive washing steps may be needed to further improved removal efficiency, predict and model removal efficiencies when multiple washing steps are applied.

\section{Acknowledgment}

The author wishes to acknowledge the contributions of Salifu, Samuel Enemona, Akan, Nyaknno Edet and Oluyide, Bibire Temitope particularly on the field, experimental setups and laboratory analysis.

\section{Conflict of interest}

The author declares no conflict of interest.

\section{References}

[1]. J. Nouri, N. Khorasani, B. Lorestani, M. Karami, A.H. Hassani, N. Yousefi, Accumulation of heavy metals in soil and uptake by plant species with phytoremediation potential, Environ Earth Sci. 59 (2009) 315-323.

[2]. A. Boularbah, C. Schwartz, G. Bitton, W. Aboudrar, A. Ouhammou, J.L. Morel, Heavy metal contamination from mining sites in South Morocco: 2. Assessment of metal accumulation and toxicity in plants, Chemosphere 63 (2006) 811-817.

[3]. F.A. Jan, M. Ishaq, I. Lhsanullah, S.M. Asim, Multivariate statistical analysis of heavy metals pollution in industrial area and its comparison with relatively less polluted area: a case study from the City of Peshawar and district Dir Lower, J. Hazard. Mater. 176 (2010) 609-616.

[4]. M.K. Zhang, Y.Z Liu, H. Wang, Use of single extraction methods to predict bioavailability of heavy metals in polluted soils to rice, Communication Soil Sci. Plant Anal. 41 (2010) 820-831.

[5]. H.B. Li, S. Yu, G.L. Li, Y. Liu, G.B. Yu, H. Deng, S.C. Wu, M.H. Wong, Urbanization increased metal levels in lake surface sediment and catchment topsoil of waterscape parks, Sci. Total Environ. 432 (2012) 202-209.

[6]. K. Lock, C.R. Janssen, Influence of ageing on copper bioavailability in soils, Environ. Toxicol. Chemistry 22 (2003) 1162-1166.

[7]. B. Nowack, R. Schulin, J. Luster, Metal fractionation in a contaminated soil after reforestation: Temporal changes versus spatial variability, Environ. Pollut. 158 (2010) 3272-3278.

[8]. N. Bolan, A. Kunhikrishnan, R. Thangarajan, J. Kumpiene, J. Park, T. Makino, M.B. Kirkham, K. Scheckel, Remediation of heavy metal(loid)s contaminated soils - to mobilize or to immobilize?, J. Hazard. Mater. 266 (2014)141-166.

[9]. R.E. Cameron, Guide to site and soil description for hazardous waste site characterization. Volume 1: Metals. Environmental Protection Agency EPA/600/4-91/029 (1992).

[10]. W. Ling, Q. Shen, Y. Gao, X. Gu, Z. Yang, Use of bentonite to control the release of copper from contaminated soils, Australian J. Soil Res. 45 (2007) 618-623.

[11]. GOC, Remediation technologies: A reference manual. Contaminated sites working group. Ontario, Chapter 6 (2003).

[12]. GWRTAC, Remediation of metals-contaminated soils and groundwater. Tech Rep. TE-97-01, GWRTAC, Pittsburgh, Pa, USA, GQRTAC-E series (1997).

[13]. M.I. Kuhlman, T.M. Greenfield, Simplified soil washing processes for a variety of soils, J. Hazard. Mater. 66 (1999) 31-45.

[14]. M. Udovic, D. Lestan, EDTA and $\mathrm{HCl}$ leaching of calcareous and acidic soils polluted with potentially toxic metals: remediation efficiency and soil impact, Chemosphere 88 (2012)718-724.

[15]. M.H. Lee, I.S. Paik, W.H. Do, I.S. Kim, Y.S. Lee, S.H. Lee, Soil washing of As-contaminated stream sediments in the vicinity of an abandoned mine in Korea, Environ. Geochem. Health. 29 (2007) 19329. 
[16]. L. Jean-Soro, F. Bordas, J.C. Bollinger, Column leaching of chromium and nickel from a contaminated soil using EDTA and citric acid, Environ. Pollut. 164 (2012) 175-181

[17]. E.U. Etim, Lead removal from contaminated shooting range soil using acetic acid potassium chloride washing solution and electrochemical reduction, J. Health Pollut. 13 (2017) 22-34.

[18]. B. Kos, L. Domen, Induced phytoextraction/soil washing of lead using biodegradable chelate and permeable barriers, Environ. Sci. Technol. 37 (2003) 624-9.

[19]. X. Ou-Yang, J.W. Chen, X.G. Zhang, Advance in supercritical $\mathrm{CO}_{2}$ fluid extraction of contaminants from soil, Geolog. Bullet. China. 29 (2010) $1655-$ 61.

[20]. B.E. Reed, P.C. Carriere, R. Moore, Flushing of Pb (II) contaminated soil using $\mathrm{HCl}$, EDTA, and $\mathrm{CaCl}_{2}$, J. Environ. Eng. 122 (1996) 48-50.

[21]. G. Dermont, M. Bergeron, G. Mercier, M. RicherLafieche, Soil washing for metal removal: A review of physical/chemical technologies and filed applications, J. Hazard. Mater. 152 (2008) 1-31.

[22]. L.G. Torres, R.B. Lopez, M. Beltran, Removal of As, $\mathrm{Cd}, \mathrm{Cu}, \mathrm{Ni}, \mathrm{Pb}$, and $\mathrm{Zn}$ from a highly contaminated industrial soil using surfactant enhanced soil washing, Physical Chem. Earth. 37 (2012) 30-36.

[23]. C.N. Mulligan, R.N. Yong, B.F. Gibbs, Surfactantenhanced remediation of contaminated soil: A review, Eng. Geol. 60 (2001) 371-380.

[24]. K.J. Hong, S. Tokunaga, T. Kajiuchi, Evaluation of remediation process with plant-derived biosurfactant for recovery of heavy metals from contaminated soils, Chemosphere 49 (2002) 37987.

[25]. C.N. Mulligan, Environmental applications for biosurfactants. Environ. Pollut. 133 (2005) 183198.

[26]. Z.M. Gusiatin, E. Klimiuk, Metal (Cu, Cd and Zn) removal and stabilization during multiple soil washing by saponin, Chemosphere 86 (2012) 383391.

[27]. W. Zhou, X. Wang, C. Chen, L. Zhu, Enhanced soil washing of phenanthrene by a plant-derived natural biosurfactant, Sapindus saponin, Colloid. Surf. A 425 (2013) 122-128.

[28]. J.P. Maity, Y.M. Huang, H. Chun-Mei, I.W. Ching, C. Chien-Cheng, L. Chun-Yi. J. Jiin-Shuh, C. Young-Fo, C. Chen-Yen, Removal of $\mathrm{Cu}, \mathrm{Pb}$ and $\mathrm{Zn}$ by foam fractionation and a soil washing process from contaminated industrial soils using soapberryderived saponin: A comparative effectiveness assessment, Chemosphere 92 (2013) 1286-1293.

[29]. R.A. Wuana, F.E. Okieimen, Heavy metals in contaminated soils: A review of sources, chemistry, risk and best available strategies for remediation. ISRN Ecology. Article ID 402647, 20 pages. Doi: 10.5402/2011/402647 (2012).
[30]. K.R. Reddy, S. Chinthamreddy, Comparison of extractants for removing heavy metals from contaminated clayey soils, Soil Sed. Contam. 9 (2000) 449-462.

[31]. R.A. Wuana, F.E. Okieimen, J.A. Imborvungu, Removal of heavy metals from a contaminated soil using organic chelating acids, Inter. J. Environ. Sci. Technol. 7 (2010) 485-496.

[32]. E.O. McLean, Soil pH and lime requirement. In: A.L. Page, R.H. Miller, D.R. Keeney (Eds.), Methods of soil analysis, American Society of Agronomy, pp. 199-223, Madison, Wisconsin, USA (1982).

[33]. International Institute of Tropical Agriculture, IITA Selected methods for soil and plant analysis. Manual series No. 1, pp. 2-6, IITA, Ibadan (2001).

[34]. A. Walkley, I.A. Black, An examination of the Degtjareff method for determining soil organic matter and proposed modification of the chromic acid titration method, Soil Sci. 37 (1984) 29-38.

[35]. R.H. Bray, L.T. Kurtz, Determination of total organic and available forms of phosphorus in soils, Soil Sci. 59 (1945) 39-45.

[36]. J.M. Bremner, C.S Mulvaney, Nitrogen-total. In: A.L. Page, R.H. Miller, D.R. Keeney (Eds.), Methods of soil analysis, American Society of Agronomy, pp. 595-624, Madison, Wisconsin, USA (1982).

[37]. J.D. Rhoades, Soluble salt. In: A.L. Page, R.H. Miller, D.R. Keeney (Eds.), Methods of soil analysis, Part 2. American Society of Agronomy, pp. 167-180, Madison, Wisconsin, USA (1982).

[38]. H. Niskavaara, C. Reimann, V. Chekushin, G. Kashulina, Seasonal variability of total and easily leachable elements in top soils $(0-5 \mathrm{~cm})$ from eight catchments in the European artic (Finland, Norway and Russia), Environ. Pollut. 96 (1997) 261-74.

[39]. A. Tessier, P.G.C. Campbell, M. Bisson, Sequential extraction procedures for the speciation of particulate trace metals, Anal. Chem. 51 (1979) 844-881.

[40]. B.J. Alloway, Soil processes and the behavior of metals, Blackie Academic and Professional, London (1997).

[41]. E.U. Etim, P.C. Onianwa, Lead contamination of soil in the vicinity of a military shooting range in Ibadan, Nigeria, Toxicol. Environ. Chem. 94 (2012) 895-905.

[42]. W. Li, R.W. Peters, M.D. Brewster, G.A. Miller, Sequential extraction evaluation of heavy metals contaminated soils: How clean is clean? In: Proceedings of the Air and Waste Management Association, $88^{\text {th }}$ Annual Meeting and Exhibition, San Antonio, Texas (1995).

Received: 11.03 .2019

Received in revised form: 29.03.2019

Accepted: 30.03.2019 